\title{
An Aesthetic Study of Ancient Chinese Celadon Ware Culture
}

\author{
Yuan Yihong \\ School of Design, South China University of Technology, Guangdong, Guangzhou, 510006
}

Keywords: ancient Chinese celadon ware culture; aesthetic study; aesthetic thought

\begin{abstract}
China is a nation of chinaware and has a long history of ceramic art. Ancient Chinese celadon ware culture has a high aesthetic research value. Based on this, this paper studies the aesthetic value of ancient Chinese celadon ware culture, briefly introduces this culture, and then makes a further analysis of the aesthetic characteristics of its modeling culture and finally discusses the aesthetic thought reflected from ancient Chinese celadon wares with a view to making contributions to the inheritance and development of Chinese celadon ware culture.
\end{abstract}

\section{Introduction}

Celadon is one of the famous traditional porcelain in China. Firstly apply green glaze on the base, that is, the turquoise glaze with iron as colorant, and fire it in reducing flame, then you'll get celadon ware. The celadon ware has a long history and various types, such as Yue Kiln in Tang Dynasty, the Imperial Kiln, Ru Kiln, Longquan Kiln, Yaozhou Kiln in Song Dynasty, etc. They all belong to the celadon system. Celadon not only has fine and delicate porcelain, bright and smooth lines, but also has distinctive modeling: dignified and simple, pure, beautiful and gorgeous. In the past dynasties, the aristocrats and the common people as well, were all attracted to them. In promoting the development of their culture, they also endow the celadon ware with rich aesthetic ideas.

\section{Overview of Ancient Chinese Celadon Ware Culture}

Chinese celadon ware culture has developed from primitive state to mature state, from low level to advanced level, during which the baking technology has improved. Meanwhile, it has been influenced by social politics and cultural styles of dynasties. It varies from original celadon to the celadon in Tang Dynasty and to the celadon in Song and Yuan Dynasties. Celadon ware in each era embodies the corresponding ancient culture.

As early as 3500 ago, the primitive celadon had appeared in Zhengzhou area of Henan Province, when it was mainly used by civilians and slaves. With the development of porcelain baking technology, the scope of use it further expanded. According to statistics, in Western Zhou Dynasty, the original celadon has evolved into pots, cans, spoons and other forms. Meanwhile, in the period of Wei, Jing, South and North dynasties, celadon culture began to take shape. Later, when it was blended with Buddhist culture, celadon ware such as Lotus Vases, Yuhu Spring Bottles appeared in places. In the same period, porcelain has begun to have other varieties like white porcelain, black porcelain, and it began to enter the nobility and scholar-official class, transforming from the rough things used by rough stuff into elegant works of art.

The celadon in Tang Dynasty was the heyday of China's celadon culture, when Celadon not only had a cultural atmosphere, but also served as a messenger of cultural exchanges at home and abroad. Being continually sold abroad, celadon ware had been a synonym for Chinese culture and was called "The representative of oriental art culture". At that time, scholar-official class in Tang Dynasty continued to develop. The characteristics of celadon ware such as simplicity, elegance and natural beauty conformed to the aesthetic tendency of scholar-officials. As a result, there was a high demand for the celadon ware which greatly promoted the development of celadon industry. For some literati, celadon was the best item to express their personal sentiments. Thus, there appeared poetic lines such as "In deep autumn, the fields look rough with frosts and hoary dews; as long as 
the Yue Kiln is opened, emerald peaks present themselves" to praise celadon wares. Such an approach promoted the development of ancient celadon culture in our country and made it evolve into a kind of cultural image like "Merlin Chrysanthemum", symbolizing the good qualities of noble sentiment and not associating with evil people.

The song dynasty was the mature period of celadon culture, when the porcelain kilns such as Jingdezhen Kiln and Longquan Kiln successively appeared, which made faience (painted porcelain) replace the once dominant monochrome glaze and consequently the faience represented by blue flowers became the mainstream variety of porcelain. In the reign of Emperor Kangxi, there were many folk kilns and a few imperial kilns. Apple Green Glaze Chrysanthemum Petals Bottle is the representative work, which is seamless, quiet, elegant, and very valuable with its glaze as green as green apples.

\section{The Aesthetic Characteristics of Celadon Wares' Moulding in Ancient China}

For the cultural changing of ancient Chinese celadon wares's moulding, it was usually given perceptions of utility value. In Song dynasty, people reduced their demand of the utility of celadon wares, however, they increased their interests in such celadon those were filled with ornament and artistry, which made a great success in the moulding of celadon wares during this period. Take the celadon kiln of Song Dynasty for example, the types of celadon wares' moulding mainly included bowls, bottle and figurines, of which the bowls were mainly used by the royal and the nobility. According to the reacts of the uses, Celadon makers should pay more attention to the ornamental of the celadon wares. Thus, the aesthetic value about the Song celadon kiln, often got over its utility value, being decorative works of art. As for the moulding of Song celadon kiln, it highlighted feature is succinct, glazed simplistic and tasteful lines, instead of many flaring patterns on the surface. For instance, Song celadon kiln lotus flower bowls, with simplistic line design and without decorating bright colors or layers, show us a simple and elegant temperament.

Longquan celadon wares in Song dynasty were also a vital part of the culture of celadon, among them, the culture of drinking vessels of celadon wares had been greatly developed during this period. And the types of Longquan celadon drinking vessels were affluent, including storage, pouring drinking vessels, feathers and other antique drinking vessels. Archaistic celadon ware flourished in Song dynasty. And the wine cup is a kind of sacrificial vessel to hold wine in the earlier time. In Song Dynasty, there emerged ceramic wine vessels and archaized Gu vessels. The ceramic wine vessels produced in Longquan kiln were generally about twenty centimeters high, with a small and exquisite moulding, an external horn mouth, and an oblate abdomen. On the its neck, abdomen and shin are all tasted of sectors. In color, it is filled with green glaze, renew the glaze layer, and there is not much graced glaze on it.

There are rich types of celadon wares in Song dynasty, whose mouldings were also various. People often used them in their daily lives, or for banquets or for ritual. They also displayed and enjoyed them at that time. But in the whole, the moulding of the celadon is not only looked simple and lively but also made a much carefully deal for them, especially to the deal of the celadon's mouth and bottle of it, which is so subtle that was increased a whole aesthetic.

\section{The Reflection of Aesthetic Thought in Chinese Ancient Celadon Wares}

All kinds of wares which were inherited from ancient China are important material evidence that carry the ancient Chinese culture. Its value and ability to provide information lie not only in the presentation of its own formation and development, but also in the behind meaning of the non-physical evidence, which includes culture, society, religion and so on. And the ancient Chinese celadon can well reflect the aesthetic thought of different times.

The paper takes the celadon wares of Song dynasty as an example. We learn from all kinds of poetry and literature that the people live in Song dynasty advocated quite and plain. So, when research on the celadon wares of Song dynasty, we will find that the wares are often concise in shape, and the beauties they show are often gentle and reserved. The aesthetic thought contained in 
the celadon of Song dynasty is closely related to the aesthetics of Neo-Confucianism at that time. Cheng Zhu's Neo-Confucianism is the mainstream academic thought in the Song dynasty. As an integral part of the Neo-Confucianism system, the Taoist view clearly shows the aesthetic pursuit of Neo-Confucianism in the Song dynasty, that is the perfect unity and coordination between objective content and external image. And the ethical aesthetics of this time show on the celadon wares are simple shape, plain decoration and elegant glaze.

Antique aesthetic is similar to the contemporary retro aesthetic. However, in ancient China, antique mainly refers to the ritual and shape of wares. Celadon antique originated from the feudal society, when people had the same pursuit of etiquette and aesthetics, and they summed up the advantages of practical wares and the aesthetic wares in different times, regions, and materials. Then, when they making celadon, they could optimize its practical function, display the most beautiful modeling language and production process, and finally, make a complete art ${ }^{[3]}$. In the Song dynasty, antique is popular. People antiqued not only the shape of bronze and jade ware from different dynasties, but also the cups, bottles and jars made by other kilns from different dynasties. There was a qualitative leap in the manufacture and aesthetic value of celadon ware.

In the development process, the celadon gradually shows the character of jade. However, celadon contains more profound culture than that of jade, and with both straight and elegant in it's overall style. The celadon ware culture reflects aesthetic thought of different times, as it develops from the initial practical culture into the materialized culture of spirit and aesthetic consciousness, which formed in order to meet the needs of all social strata for spiritual and material culture. In the development of Chinese celadon ware, the pursuit of the beauty of jade was the highest realm of aesthetics, and it was shown in the celadon. With the character of conciseness, simplicity, and purity, the Chinese celadon shows a variety of beauty. It also shows the pursuit of decoration, that is the original celadon glaze colour. For example, the bright and delicate glaze of official kiln celadon and LongQuan kiln celadon wine container in Song dynasty makes people feel soft and elegant, just like the feeling of jade.

\section{Conclusion}

In summary, researches on the aesthetics of Chinese celadon ware culture are of great significance to carry forward Chinese celadon culture. Correlation analysis shows that there are not only high aesthetic value in the modeling culture of celadon, but also high research value in the modeling and decoration aesthetic. The aesthetic values and aesthetic thoughts shown in the celadon wares, which produced in different dynasties or just different kiln of the same dynasty, are different, but there are also some commonalities, that is the embodiment of social fashion of that time. Due to the limitation of article length, there are some points have not be discussed, thanks for your understanding.

\section{Acknowledgement}

Project: 2017 National Social Science Fund general project “An Aesthetic Study of Ancient Chinese Celadon Ware Culture” (Grant No. 17BZX118)

\section{References}

[1] Li Maolin. "Research on the Glazing Art and Aesthetic Characteristics of Longquan Celadon" [J]. Standards\&Quality of Light Industry, 2014(06):60-62.

[2] Xu Min. "The Beauty and Refresh of Celadon — Exploring the Aesthetics of Celadon from the Work 'The Breeze and Lotus Shadow'” [J]. ShanDong Ceramics, 2013,36(06):44.

[3] Li Xiaolei. "The Influence of Metaphysics Aesthetics in Wei and Jin Dynasties on Celadon Art” [J]. Social Science Front, 2011(07):60-61. 